\title{
Rectal reaction to injected ulcerative colitis leucocytes and plasma
}

\author{
SIDNEY FINK, WILLIAM J. DONNELLY, AND VICTOR R. JABLOKOW
}

From the Medical and Laboratory Services, Veterans Administration Hospital, Hines, Department of Medicine, Loyola University, Stritch School of Medicine, Hines, and Department of Pathology, University of Illinois, Chicago, Illinois, U.S.A.

EDITORIAL COMMENT In patients with ulcerative colitis viable leucocytes from their peripheral blood injected into the rectal mucosa caused a local reaction which was not seen after injection with plasma, a phenomenon which needs further study.

Leucocytes from the peripheral blood of patients with chronic ulcerative colitis are cytotoxic for foetal colon cells in tissue culture (Perlmann and Broberger, 1963). This report describes the effect of autologous ulcerative colitis leucocytes and cell-free plasma upon intact rectal mucosa.

\section{MATERIALS AND METHODS}

PATIENTS Seventeen ambulatory adult males with wellestablished diagnoses of chronic ulcerative colitis were studied. Rectal biopsies were compatible in each case. Patients were chosen who were in clinical remission, and without friable or ulcerating mucosa at the time of the investigation. Fifteen patients had been taking salicylazosulphapyridine (Azulfidine) for six to 24 months. None had been taking adrenal steroids during the preceding three months (Table I). Four patients with Laennec's cirrhosis and three with duodenal ulcer were also tested.

PREPARATION OF MATERIAL Autologous leucocytes were obtained from venous blood by the method of Friedman, Bardawil, Merril, and Hanau (1960). A $30 \mathrm{ml}$. syringe containing $100 \mathrm{mg}$. of heparin (Liquaemin sodium, Organon) and $400 \mathrm{mg}$. of dextran in $20 \%$ aqueous solution was used to collect $27 \mathrm{ml}$. of blood. The needle was capped and the syringe placed in a vertical position at $4^{\circ} \mathrm{C}$. for one hour. The buffy coat and plasma layers were then expressed into a centrifuge tube and centrifuged at 1,000 r.p.m. for 10 minutes. The supernatant clear plasma was pipetted off and approximately $1 \mathrm{ml}$. of cellular sediment-containing plasma was left. This $1 \mathrm{ml}$. contained $2.5 \times 10^{7}$ white blood cells, platelets, and a small number of red blood cells. In seven experiments, $0.5 \mathrm{ml}$. of this fluid was transferred to a sonic oscillator ${ }^{1}$ and oscillated at $9 \mathrm{kc}$. per second for 10 minutes. These

${ }^{\mathbf{I}}$ Raytheon magnetostriction sonic oscillator model S-102A. preparations were examined by direct phase microscopy and repeatedly oscillated until all the cells seen were pyknotic and showed marked morphological change. These suspensions were used for injection when the morphological changes fulfilled the criteria of Schrek (1958) for non-viability, and are henceforth referred to as 'non-viable leucocytes' in this report. An aliquot of the supernatant plasma was placed in a Neubauer counting chamber and scanned for white blood cells. This plasma was re-centrifuged if necessary and used for injection when the microscopic examination failed to demonstrate leucocytes. This plasma is hereafter referred to as leucocyte-free.

PROCEDURE Two hours after a $135 \mathrm{ml}$. sodium biphosphate enema (Fleet) ${ }^{2}, 33$ separate injections of $0.1 \mathrm{ml}$. of leucocyte-free plasma and of $0.1 \mathrm{ml}$. of plasma containing $2-5 \times 10^{6}$ intact leucocytes were made into two areas of rectal mucosa approximately $9 \mathrm{~cm}$. from the anus. The lowest valve of Houston was taken as a reference point, and the injections were given through a short proctoscope, using a tuberculin syringe and 23 gauge tonsil needle. Five of the patients with ulcerative colitis had two injections, separated by a seven-to-14-day interval, and two of them received three injections over a 21-day period.

Seven patients with ulcerative colitis received simultaneous injections of $0 \cdot 1 \mathrm{ml}$. plasma containing non-viable leucocytes and $0.1 \mathrm{ml}$. of plasma containing intact leucocytes.

In the first five experiments, the injected areas were examined through a proctoscope at frequent intervals during the first day, and at 24,48 , and 72 hours. In all subsequent experiments proctoscopy was done at one and two to three hours after injection, and the injected areas were biopsied at the time of the second proctoscopy. A total of 27 paired biopsies of injected areas was taken in 13 patients with colitis. This includes seven specimens ${ }^{2} \mathrm{C}$. B. Fleet Co., Lynchburg, Va. 
taken in the experiments with non-viable cells. Recent rectal biopsies were available in seven of these patients. In the other six, a control biopsy was taken just before the injections were made. Three of the patients without ulcerative colitis were also biopsied before and after injection. The specimens were fixed in formalin, processed routinely, and stained with haematoxylin and eosin.

\section{RESULTS}

Injected viable leucocytes caused a clearly visible local reaction in 14 of the 17 patients with ulcerative colitis (Tables I and II). Repeated experiments were positive in six out of seven patients with a final total of 27 reactions seen after 33 injections. Injected nonviable leucocytes caused a gross reaction in two out of seven experiments. Contrasted with these findings, no reaction was observed in any of the 33 areas which were injected with plasma alone. No reaction to either injected plasma or leucocytes was seen in the
TABLE I

CLINICAL SUMMARY OF 17 PATIENTS WITH CHRONIC ULCERATIVE COLITIS INJECTED WITH AUTOLOGOUS LEUCOCYTES

\begin{tabular}{lcclc} 
Patient & Age & $\begin{array}{c}\text { Duration of } \\
\text { Colitis }(y r .)\end{array}$ & Drugs & $\begin{array}{l}\text { Rectal } \\
\text { Reaction }\end{array}$ \\
\hline A.T. & 63 & 1 & Azulfidine & + \\
G.W. & 50 & $\frac{1}{2}$ & None & + \\
V.V. & 46 & 14 & Azulfidine & + \\
A.G. & 72 & 7 & Azulfidine & + \\
B.D. & 36 & 2 & Azulfidine & + \\
G.K. & 57 & 12 & Azulfidine & + \\
E.E. & 40 & 2 & Azulfidine & + \\
W.D. & 29 & 8 & Azulfidine & + \\
K.G. & 29 & 12 & Azulfidine & + \\
J.W. & 45 & 3 & Azulfidine & + \\
R.L. & 57 & 10 & Azulfidine & - \\
R.D. & 31 & 3 & None & - \\
A.B. & 33 & 4 & Azulfidine & + \\
S.R. & 43 & 3 & Azulfidine & + \\
F.V. & 45 & 15 & Azulfidine & + \\
J.F. & 39 & 3 & Azulfidine & - \\
W.L. & 46 & 2 & Azulfidine & +
\end{tabular}

TABLE II

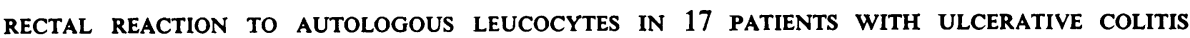
Patient $\begin{aligned} & \text { Appearance of Mucosa Change } \\ & \text { before Injection }\end{aligned}$
Histology

Control Plasma Viable

Leucocytes

\begin{tabular}{lll}
\hline A.T. $2 \times$ & Atrophic & Branching vessels, petechiae $(2 \times)$ \\
G.W. $2 \times$ & Mildly hyperaemic & Marked hyperaemia
\end{tabular}

V.V. Marked engorgement

A.G. Atrophic

B.D. $3 \times \quad$ Hyperaemic

G.K. $2 \times$ Atrophic

E.E. $3 \times \quad$ Hyperaemia; normal

W.D. Hyperaemic

K.G. Normal

J.W. Mildly hyperaemic

R.L. $2 \times \quad$ Mildly hyperaemic

R.D. Normal

A.B. $2 \times \quad \begin{aligned} & \text { Normal; mildly } \\ & \text { hyperaemic }\end{aligned}$

S.R. Mildly hyperaemic

F.V. Hyperaemic

J.F. Normal

W.L. Marked hyperaemia
Gross haemorrhage about injection site

Hyperaemia, branching vessels

Hyperaemia, scattered petechial haemorrhages

Hyperaemia, branching vessels, petechiae $(2 \times)$

Hyperaemia, petechiae; no change

Petechial haemorrhages

No change

Marked congestion, vascular dilatation

Petechial haemorrhages $(2 \times)$

No change

No change, congestion, vascular dilatation

Marked local congestion, hyperaemia

Multiple petechial haemorrhages

No change

Gross haemorrhage
Marked chronic inflammatory changes in all

Mild degree of inflammatory Acute
vasculitis \begin{tabular}{c}
\hline Acute \\
vasculitis $(2 \times)$
\end{tabular} changes

No biopsy

No biopsy

Chronic inflammatory changes

Acute vasculitis $(2 \times)$

No biopsy

Chronic inflammatory changes

Focal haemorrhages, no vasculitis first $2 \times$

Marked chronic inflammatory changes in all

Mild chronic inflammation Early acute
vasculitis

Chronic inflammatory changes and acute vasculitis in all

Chronic inflammation

Chronic inflammation, mild, in all

Mild degree of chronic inflammation in all

Mild degree of chronic inflammatory changes in all

No biopsy

Mild degree of inflammatory changes in all

No biopsy 


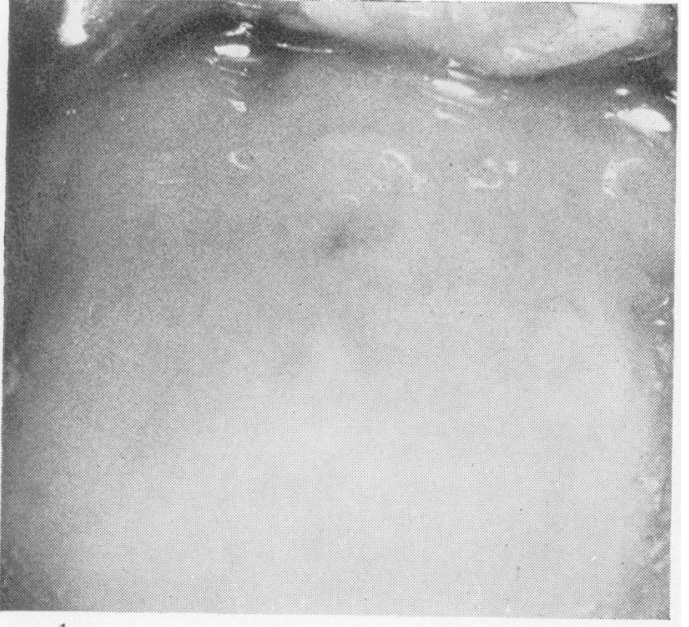

FIG. 1a

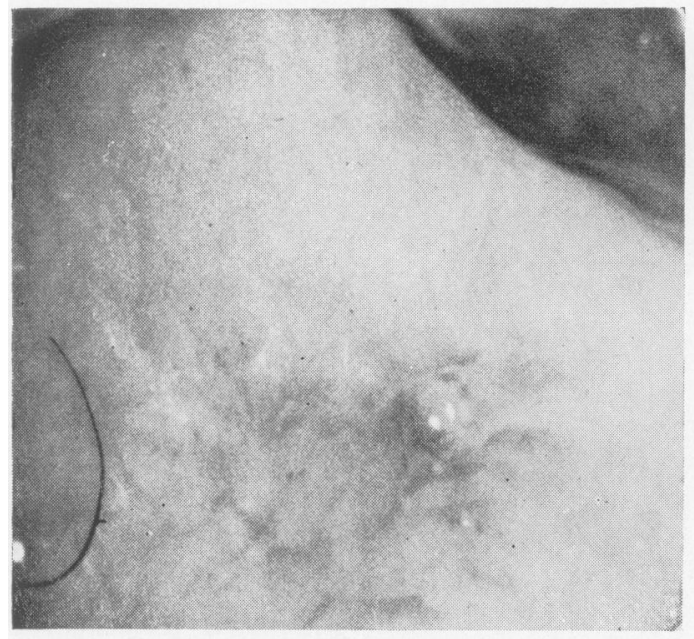

FIG. $1 \mathrm{~b}$

FIG. 1. Appearance of rectal mucosa one hour (1a) and two and a half hours (1b) after injection of autologous leucocytes in a patient with ulcerative colitis.

seven patients who did not have ulcerative colitis.

The reaction to injected leucocytes appeared two to three hours after injection, and was characterized by varying degrees of vascular dilatation, hyperaemia, and haemorrhage. In the five experiments in which biopsies were not done, the mucosa assumed its original appearance in two to three hours. The reaction was most marked in mucosae which were hyperaemic and engorged before injection (Fig. 1).

Microscopic examination of specimens taken from patients with ulcerative colitis all showed varying degrees of acute and chronic inflammation. No specific change characterized biopsy specimens from the areas in which a reaction to injected leucocytes had been observed. It was noted, however, that an acute vasculitis in the submucosa was present in eight out of 15 of these specimens (Table II), and in one of the instances where disrupted leucocytes caused a reaction. Acute vasculitis was also found in biopsies of areas which did not show a visible reac-

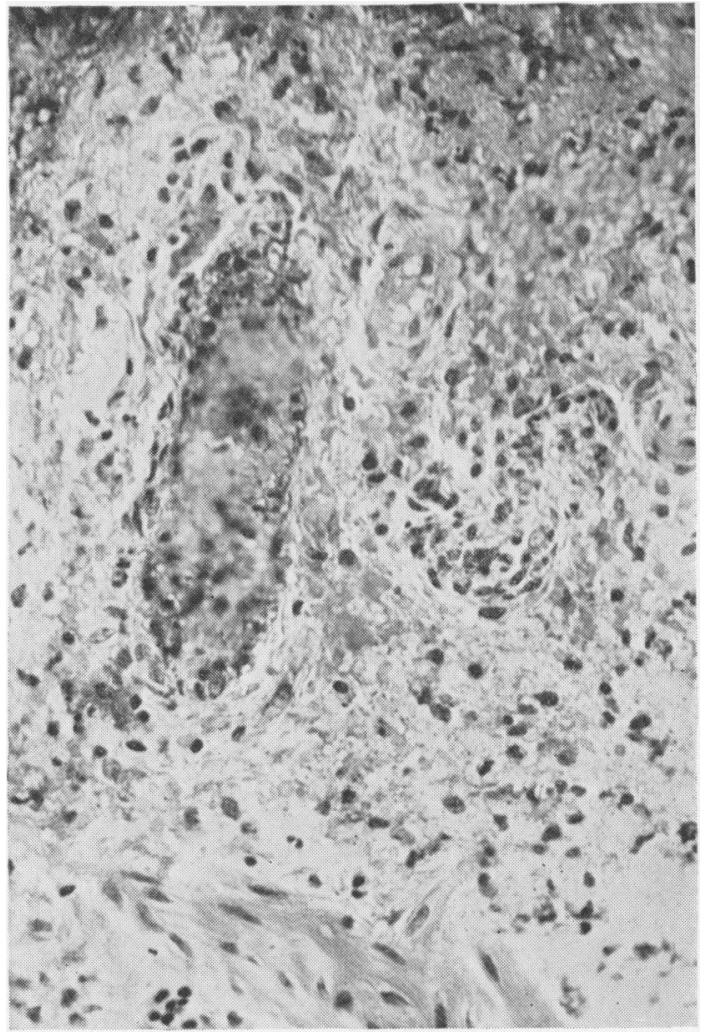

FIG. 2. Specimen of ulcerative colitis rectal mucosa taken two hours after leucocyte injection, showing acute vasculitis with inflammatory changes in vessel walls and vascular necrosis (haematoxylin and eosin $\times 300$ ).

tion but had been injected with viable leucocytes $(\times 1)$, disrupted leucocytes $(\times 1)$, plasma $(\times 2)$, and in control biopsies taken from one patient with ulcerative colitis and one patient with duodenal ulcer who had no other evidence of rectal pathology. The vasculitis varied in appearance from an early change, with lining of epithelium by polymorphonuclear leucocytes and early diapedesis of these cells, to a stage in which widespread vascular wall necrosis and an intense inflammatory infiltrate was seen (Fig. 2). In most instances there was accompanying oedema and hyperaemia in the surrounding tissue. 


\section{DISCUSSION}

The gross appearance of the vascular reaction we observed is typical of that seen in allergic reactions (Stetson, 1951; Rider and Moeller, 1963), and one may speculate that the injected lymphocytes were responsible for the reaction. The pathological findings and time sequence were not typical of those seen in cutaneous delayed sensitivity reactions, but these differences may be due to the tissue involved. A chronic delayed hypersensitivity reaction has been described in the guinea-pig colon (Bicks and Rosenberg, 1964), but has not yet been described in the colon of man. It has been suggested that ulcerative colitis lymphocytes carry an antibody which reacts with colonic mucosa (Broberger, 1964), and fluorescent antibody stains have shown fluorescence in the cellular infiltrate of rectal biopsies from cases of ulcerative colitis (Kirsner, 1965). Our finding is an additional indication that further immunological study of the ulcerative colitis lymphocyte is needed. The possiblity that the rectal reaction is caused by a lysosomal component of the polymorphonuclear leucocytes (Janoff, Scherer, and Bean, 1965) should also be explored.

\section{SUMMARY}

Intramucosal rectal injections of intact autologous leucocytes were made in 17 patients with chronic ulcerative colitis. A local reaction characterized by varying degrees of vascular dilatation, hyperaemia, and haemorrhage was seen in 14 patients. The reaction was also seen in two of seven experiments in which non-viable leucocyctes were used, but not after injection of cell-free plasma. Injection of autologous leucocytes did not cause a reaction in seven patients who did not have ulcerative colitis. These findings suggest further study of the possible role of the ulcerative colitis leucocyte in the pathogenesis of this disease.

We gratefully acknowledge the technical assistance of Miss Mary Spinuzza, B.S.

\section{REFERENCES}

Bicks, R. O., and Rosenberg, E. W. (1964). A chronic delayed hypersensitivity reaction in the guinea pig colon. Gastroenterology, 46, 543-549.

Broberger, O. (1964). Immunologic studies in ulcerative colitis. Ibid., 47, 229-240.

Friedman, E. A., Bardawil, W. A., Merrill, J. P., and Hanau, C. (1960). 'Delayed' cutaneous hypersensitivity to leukocytes in disseminated lupus erythematosus. New Engl. J. Med., 262, 486491.

Janoff, A., Schaefer, S., Scherer, J., and Bean, M. A. (1965). Mediators of inflammation in leukocyte lysosomes. 1I. mechanism of action of lysosomal cationic protein upon vascular permeability in the rat. J. exp. Med., 122, 841-851.

Kirsner, J. B. (1965). The present status of immunologic observations in ulcerative colitis. Surg. Clin. N. Amer., 45, 1199-1209.

Perlmann, P., and Broberger, O. (1963). In vitro studies of ulcerative colitis. II. cytotoxic action of white blood cells from patients on human fetal colon cells. J. exp. Med., 117, 717-733.

Rider, J. A., and Moeller, H. C. (1963). Hypersensitivity factors in ulcerative colitis. J. Amer. med. Ass., 183, 545-546.

Schrek, R. (1958). Slide-chamber method to measure sensitivity of cells to toxic agents. Arch. Path., 66, 569-576.

Stetson, C. A., Jr. (1951). Similarities in the mechanisms determining the Arthus and Shwartzman phenomena. J. exp. Med., 94, 347-358. 